\title{
Radiofrequency Ablation is Associated with Decreased Neoplastic Progression in Patients with Barrett's Esophagus and Confirmed Low-Grade Dysplasia
}

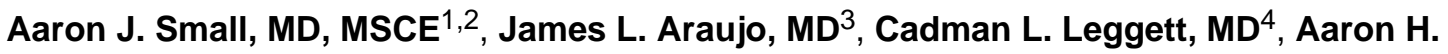 \\ Mendelson, MD $^{1}$, Anant Agarwalla, MD ${ }^{5}$, Julian A. Abrams, MD, MPH $^{3}$, Charles J. Lightdale, \\ MD 3 , Timothy C. Wang, MD ${ }^{3}$, Prasad G. lyer, MD, MS ${ }^{4}$, Kenneth K. Wang, MD ${ }^{4}$, Anil K. \\ Rustgi, MD ${ }^{1}$, Gregory G. Ginsberg, MD ${ }^{1}$, Kimberly A. Forde, MD, MHS ${ }^{1,2}$, Phyllis A. \\ Gimotty, PhD $^{2}$, James D. Lewis, MD, MSCE ${ }^{1,2}$, Gary W. Falk, MD, MS $^{1,2}$, and Meenakshi \\ Bewtra, MD, MPH, PhD ${ }^{1,2}$ \\ ${ }^{1}$ Department of Medicine, Division of Gastroenterology, Perelman School of Medicine, University \\ of Pennsylvania, Philadelphia, PA \\ ${ }^{2}$ Department of Biostatistics and Epidemiology, Perelman School of Medicine, University of \\ Pennsylvania, Philadelphia, PA \\ ${ }^{3}$ Department of Medicine, Division of Digestive and Liver Diseases, Columbia University Medical \\ Center, New York, NY \\ ${ }^{4}$ Department of Medicine, Division of Gastroenterology, Mayo Clinic, Rochester, MN \\ ${ }^{5}$ Perelman School of Medicine, University of Pennsylvania, Philadelphia, PA
}

\section{Abstract}

Background \& Aims-Barrett's esophagus (BE) with low-grade dysplasia (LGD) can progress to high-grade dysplasia (HGD) and esophageal adenocarcinoma (EAC). Radiofrequency ablation (RFA) has been shown to be an effective treatment for LGD in clinical trials but its effectiveness in clinical practice is unclear. We compared the rate of progression of LGD following RFA to that with endoscopic surveillance alone in routine clinical practice.

Methods-We performed a retrospective study of patients who either underwent RFA ( $n=45)$ or surveillance endoscopy $(n=125)$ for LGD, confirmed by at least 1 expert pathologist, from October 1992 through December 2013 at 3 medical centers in the US. Cox regression analysis was used to assess the association between progression and RFA.

Results-Data were collected over median follow-up periods of 889 days (inter-quartile range, 264-1623 days) after RFA and 848 days (inter-quartile range, 322-2355 days) after surveillance

Address for Correspondence: Aaron J. Small, M.D., M.S.C.E., Gastroenterology Division, Virginia Mason Medical Center, 1100 Ninth Avenue, Buck Pavilion, Level 3, Seattle, WA 98104, U.S.A. Telephone: 206-223-2319, asmall27@ gmail.com. The authors have no personal or financial conflicts of interest in any content or products mentioned in this manuscript.

Publisher's Disclaimer: This is a PDF file of an unedited manuscript that has been accepted for publication. As a service to our customers we are providing this early version of the manuscript. The manuscript will undergo copyediting, typesetting, and review of the resulting proof before it is published in its final citable form. Please note that during the production process errors may be discovered which could affect the content, and all legal disclaimers that apply to the journal pertain. 
endoscopy $(P=.32)$. The annual rates of progression to HGD or EAC was $6.6 \%$ in the surveillance group and $0.77 \%$ in the RFA group. The risk of progression to HGD or EAC was significantly lower among patients who underwent RFA than those who underwent surveillance (adjusted hazard ratio, 0.06; 95\% confidence interval, 0.008-0.48).

Conclusions-Among patients with BE and confirmed LGD, rates of progression to a combined endpoint of HGD and EAC were lower among those treated with RFA than among untreated patients. Although selection bias cannot be excluded, these findings provide additional evidence for the use of endoscopic ablation therapy for LGD.

\section{Keywords}

eradication; clinical setting; prevention; esophageal cancer

\section{INTRODUCTION}

The incidence of esophageal adenocarcinoma (EAC) continues to rise at a rate greater than any other cancer in the Western world and is associated with poor survival. ${ }^{1}$ Barrett's esophagus (BE) is a well-established precursor of EAC. ${ }^{2,3}$ Despite its limitations, dysplasia is still the most predictive biomarker for progression of BE to EAC, with dysplasia severity correlating with risk of cancer. ${ }^{4,5,6}$ Endoscopic eradication of Barrett's mucosa has become an acceptable strategy to reduce risk of high-grade dysplasia (HGD) or intramucosal carcinoma (IMC) progressing to invasive EAC. However, the optimal approach to management of low-grade dysplasia (LGD) remains uncertain due, in part, to inconsistent reports of the natural history of LGD. ${ }^{3,4,6,7}$ Prior studies that have reported high progression rates for untreated LGD have typically included expert pathology review suggesting that misclassification of LGD may contribute to lower progression rates in some studies. $6,7,8,9,10,11,12$

Current guidelines suggest performance of endoscopic surveillance every 6 to 12 months after the initial detection of LGD. ${ }^{3,5}$ However, data from a recent European clinical trial suggest that radiofrequency ablation (RFA) is superior to continued endoscopic surveillance among patients with LGD confirmed by a panel of expert GI pathologists. ${ }^{13}$ As a result, the optimal approach for patients with LGD remains uncertain. ${ }^{14}$ If rates of progression are low, continued surveillance may be preferred. If rates of progression are high and RFA is effective in clinical practice as suggested by clinical trial data, RFA may be preferred. To address this uncertainty, we conducted a multicenter retrospective cohort study examining patients with LGD confirmed by expert pathologists who received RFA or continued surveillance endoscopy. We sought to: (1) define the risk of HGD/EAC after initial detection of LGD in BE patients, and (2) compare the rates of progression to HGD/EAC between patients undergoing RFA and those undergoing endoscopic surveillance. A secondary aim was to identify independent risk factors associated with progression of LGD to HGD/EAC. 


\section{METHODS}

\section{Patients and Settings}

The source cohort came from three referral centers within the Barrett's Esophagus Translational Research Network (BETRNet) consortium funded by the National Cancer Institute: the University of Pennsylvania, Columbia University, and the Mayo Clinic. Within this cohort, BE patients who had a diagnosis of LGD as verified by histopathology from October 1992 (the date of earliest registration of LGD patients available) to December 2013 were identified for study inclusion. The inclusion criteria for this study were as follows: (1) age > 18 years, (2) histology of intestinal metaplasia (IM) in biopsies obtained above the gastroesophageal junction, (3) LGD as determined by at least one GI pathologist at a BETRNet site, and (4) undergoing routine endoscopic surveillance or had endoscopic ablation following the diagnosis of LGD.

Patients with any of the following characteristics were excluded: (1) prior esophageal surgery or endoscopic therapy for BE, (2) prior diagnosis of HGD or adenocarcinoma, and/or (3) histology indefinite for dysplasia. Patients were assigned to one of two groups based on exposure to RFA: the surveillance cohort was comprised of LGD patients who had at least one endoscopy after detection of confirmed LGD; the ablation cohort was comprised of all BE patients who had undergone RFA after a diagnosis of LGD.

\section{Histopathology}

Histopathologic assessment of biopsy specimens was reported using established criteria for dysplasia (LGD, HGD) and esophageal adenocarcinoma according to the Vienna classification. ${ }^{15,16}$ Only cases with a diagnosis of LGD made at one of the three participating academic medical centers were included in this study. The worst histologic grade identified within the specimens was the overall histologic grade for that endoscopy. Each site had a group of local GI pathologists with extensive experience in Barrett's histology and neoplasia during the study period. The histopathology interpretations of dysplasia and neoplasia were read by at least one GI pathologist as part of routine practice at each site and performed at the time when endoscopic biopsies were obtained. In cases of uncertainty, a consensus diagnosis was reached between two GI pathologists in a dedicated meeting at each center. In cases of discordance between the two pathologists, a third GI pathologist was asked to interpret for consensus review as per protocol at each center. For cases when a patient was referred to the participating center with a diagnosis of LGD made at a community institution, outside slides were retrieved and reinterpreted by the participating center pathologists. Central reading of all pathology specimens was not conducted in this study.

\section{Surveillance Endoscopy and Radiofrequency Ablation}

Surveillance intervals and biopsy protocols were not standardized across all centers in this study. However cases from each center had endoscopies performed by experienced endoscopists with expertise in Barrett's esophagus who followed AGA guideline recommendations. ${ }^{3}$ Following a diagnosis of LGD, surveillance endoscopy was performed within one year unless the patient received RFA. In the ablation group, patients received 
initial RFA within one year of diagnosis of LGD. Additional description of surveillance and RFA are included in Supplemental Methods.

\section{Data Collection and Management}

Data were collected from medical records at each center and transferred to the University of Pennsylvania for analysis. Data extracted from medical records included: age at initial diagnosis of LGD, sex, race/ethnicity, endoscopy results (date of procedure, length of BE), presence of nodularity, and histologic diagnosis at each endoscopic procedure. Extent of dysplasia (spatial distribution within Barrett's segment) was recorded and assigned as multifocal if there was evidence of dysplasia on at least two specimens taken from different locations in the Barrett's segment on the same endoscopy. See Supplemental Methods for more detailed description of covariates, data extraction and management, and follow-up intervals.

\section{Study Endpoints}

The primary outcome of interest was the detection of HGD or EAC during follow-up. For the secondary aim of identifying risk factors for progression of LGD, we assessed the impact of previously defined variables (see Supplemental methods) on the rate of progression.

\section{Statistical Analysis}

Descriptive data were expressed as median (IQR) or mean (SD) as appropriate for continuous data. Chi-squared, Fisher's exact, and Mann-Whitney U test were used to assess differences between the two study groups.

The start of follow-up for each patient was the initial intervention (either the first endoscopy with RFA in the ablation group or the first endoscopy following the diagnosis of LGD in the surveillance group as to avoid immortal time bias in progression rate estimates). Follow-up ended with the last recorded endoscopy with biopsy or the first diagnosis of HGD or EAC. Data were censored if the patient was lost to follow-up. Cumulative incidence curves were used to assess yearly progression rates and were compared using the log-rank test.

Cox proportional hazard analysis was used to assess effect of RFA on progression controlling for potential confounders. Potential predictors $(\mathrm{P}<0.20$ from the univariate analyses) were included in a backward, stepwise elimination multivariate Cox hazard model. Factors that no longer had a $\mathrm{P}<0.05$ in the model were excluded to develop a final parsimonious model. All variables were evaluated for confounding or effect modification. Confounders (as determined by a $\geq 15 \%$ difference between the crude and HR adjusted for the variable of interest) were also included in the final model. Patients with missing data were excluded from multivariable analysis. Predictors of progression to HGD/EAC or absence of LGD during follow-up in the surveillance group were investigated using Cox analysis.

Several sensitivity analyses were performed. To assess for the effect of the year of diagnosis one analysis excluded cases diagnosed before 2006 (prior to use of RFA). Additional 
sensitivity analyses excluded patients with raised (nodular) LGD and cases with progression that occurred within one year surveillance.

All statistical analysis was performed using the Stata System for Macintosh, version 12 (StataCorp LP, College Station, TX). For all outcomes, a two-sided P $<0.05$ indicated statistical significance. Appropriate Institutional Review Board approval was obtained at all participating institutions.

\section{RESULTS}

\section{Patients and Barrett's Characteristics}

A total of 170 patients met inclusion criteria: 125 underwent surveillance only whereas 45 underwent RFA (Figure 1; Supplemental Figure 1). The two groups were similar in baseline characteristics, except for higher PPI use in the RFA patients and center differences in the proportion of patients undergoing ablation (Table 1). There were numerically but not statistically more visible macroscopic lesions detected in the surveillance group compared to the ablated group ( $10.4 \%$ vs. $6.6 \%, \mathrm{P}=0.45)$. Of the 13 patients with nodularity in the surveillance arm, 4 had EMR performed as initial staging prior to endoscopic surveillance. Of the 3 ablated patients with nodularity, 2 had EMR performed preceding RFA. Each of these patients had pathology consistent with LGD (i.e. no HGD or EAC detected). The baseline Barrett's segment characteristics were otherwise comparable between the two groups (Table 1). There was a higher frequency of endoscopies performed in the ablated group as would be expected due to the need to perform multiple ablation endoscopies and shorter surveillance intervals post-ablation. The median follow-up duration was 29.6 (IQR 8.8, 54.1) months in the RFA group and 28.3 (IQR 10.7, 78.5 months; $\mathrm{P}=0.32$ ) in the surveillance group.

In the ablation group, complete eradication of dysplasia was achieved in $95.6 \%$ and complete eradication of intestinal metaplasia (CE-IM) in $77.8 \%$ after RFA (Table 2). In the surveillance group, $31.2 \%$ of patients had no further dysplasia detected on endoscopic biopsies subsequent to the initial diagnosis of LGD.

\section{Incidence Rate of Progression}

Of 125 patients in the surveillance group, there was disease progression in 36 (28.8\%) over the observation period of 544.75 years. Of the 36 progressors in the surveillance group, 29 developed HGD, 5 IMC, and 2 submucosal EAC. This corresponds to an annual rate of disease progression to HGD/EAC of $6.6 \%$ and to submucosal EAC of $0.37 \%$.

One of 45 patients (2.2\%) of the ablated patients progressed to intramucosal cancer during the study period. Over the observation period of 130.1 years, this corresponded to an annual rate of disease progression to HGD/EAC of $0.77 \%$. That patient underwent one session of RFA for a $6 \mathrm{~cm}$ long, flat, multifocal LGD and did not return for subsequent surveillance endoscopy until 7.5 months post-ablation when biopsies demonstrated IMC. Subsequent eradication with EMR was performed. Additional description about management following progression is included in Supplemental Table 1. 
Progression-free survival in the surveillance group was $85.1 \%$ at one year of follow-up evaluation $(n=92) ; 75.4 \%$ at two years of follow-up evaluation $(n=68)$; and $71.7 \%$ at three years of follow-up evaluation $(n=56)$ (Figure 2). There were two patients who developed submucosal EAC; one at 22.8 months and the other at 38.3 months after initial surveillance endoscopy.

\section{Effectiveness and Disease Progression}

The risk of progression to HGD or EAC was lower among patients who were ablated than those who underwent surveillance (unadjusted HR=0.08; 95\% CI, 0.01-0.61; $P=0.02$ ), and remained so after adjusting for incident LGD (diagnosis preceded by Barrett's esophagus with no dysplasia on study entry), confirmation of LGD on a second pathology specimen, and multifocal dysplasia (adjusted [aHR] $=0.06 ; 95 \% \mathrm{CI}, 0.008-0.48 ; P=0.008$ ) (Table 3). The risk of progression following RFA remained significantly lower after adjusting for the year of LGD diagnosis (which was neither an effect modifier nor a confounder) (Table 3). In a subgroup analysis including only patients with LGD diagnosed in 2006 or later, a similar benefit was seen for RFA (25.0\% progressed to HGD or EAC in surveillance vs. $2.5 \%$ in ablation; aHR $=0.09 ; 95 \% \mathrm{CI}, 0.01-0.73$ ). The risk of progression to EAC ( $\geq \mathrm{T} 1 \mathrm{a})$ was not significantly different between the treatment groups when including all study patients $(\mathrm{aHR}=0.19,95 \% \mathrm{CI}, 0.02-1.82)$.

Macroscopic lesions were identified in 10.4\% of patients in the surveillance group and $6.6 \%$ in the ablation group. Of the patients who did not have EMR despite a visible macroscopic lesion on initial endoscopy, 6 of 9 in the surveillance patients progressed to HGD/EAC (66.7\%), one of which was EAC, while the one RFA patient with a nodule but no EMR did not progress during follow-up. When excluding patients with nodularity, the risk of progression to HGD or EAC was lower in the ablation group (1/42, 2.4\% vs. 29/112, 25.9\% in the surveillance group; $\mathrm{HR}=0.10,95 \% \mathrm{CI}, 0.01-0.76$; Table 3).

Significantly fewer patients in the ablation group had disease progression to HGD or EAC. In the first year, progression rates were $3.0 \%$ and $14.8 \%$ in the ablation and surveillance group respectively (risk difference $=11.8 \%, 95 \%$ CI, $1.0-24.5 \%$ ) (Table 4). After the first year, there were no progressors in the ablation group whereas in the surveillance group $13.9 \%, 3.4 \%$, and $8.0 \%$ progressed in years 2,3 , and 4 , respectively. The estimated cumulative risk of progression to HGD or EAC within 3 years was $2.9 \%$ (95\% CI, $0.4-$ $20.3 \%$ ) in the RFA group versus $33.0 \%$ (95\% CI, $22.9-47.6 \%$ ) in the surveillance group, corresponding to a number needed to treat (NNT) to prevent one patient from progressing within 3 years of initial intervention for LGD of 3 . Submucosal invasion developed in two patients in the surveillance group ( $1.6 \%$ vs. $0 \%$ in ablation, $\mathrm{p}=0.39)$. The estimated cumulative risk of progression to submucosal EAC within 3 years was $1.4 \%$ (95\% CI, 0.2 $10.1 \%$ ) in the surveillance group (versus nil in the RFA group), corresponding to a NNT of 70 to prevent one patient from progressing within 3 years of initial intervention for LGD. This risk increased to $3.3 \%$ (95\% CI, $0.8-3.3 \%$ ) within 5 years in the surveillance group, corresponding to a NNT of 31 . 


\section{Predictors of Progression}

In univariate analysis, longer Barrett's segments (per cm), persistent LGD, nodularity, and multifocal dysplasia were associated with progression to HGD/EAC in the surveillance group (Table 5). In multivariate analysis, presence of nodularity (HR=3.12 [95\% CI, 1.188.25] and multifocal dysplasia ( $\mathrm{HR}=3.09$ [95\% CI, 1.49-6.41]) were independent predictors of progression in the surveillance group and remained significant after adjusting for length and use of aspirin. However, among 86 patients with flat, unifocal LGD in the surveillance group, 16 progressed to HGD (18.6\%), 3 to IMC (3.5\%) and 1 to submucosal EAC (1.2\%).

Absence of LGD on subsequent surveillance endoscopies during follow-up was associated with shorter Barrett's segments (per $\mathrm{cm}$ ), active smoking status, and PPI use (Supplemental Table 2).

\section{DISCUSSION}

In this multicenter study of patients with confirmed LGD, we observed a high progression rate to HGD or adenocarcinoma in the surveillance group; however, progression rates were much lower with RFA. We estimate that for every 3 patients treated with RFA, one additional patient with LGD will avoid progression to HGD or EAC within 3 years. We were not able to demonstrate a significant reduction in EAC, although this was a rare event and as such our power to determine a difference was much less for this outcome.

Additionally, detection of HGD generally prompts an intervention prior to progression to EAC.

Prior studies have reported highly variable annual rates of LGD progression to HGD/EAC of $0.6 \%$ to $13.4 \%$ per patient-year. $6,7,11,12,17,18,19$ This variability has been attributed in part to misclassification of LGD, with higher rates of progression in European studies using expert pathology evaluation of LGD. ${ }^{7,12}$ The diagnosis of LGD in community settings is challenging with up to $85 \%$ of initially diagnosed LGD being downgraded following interpretation by a GI pathologist at an academic referral center. ${ }^{7,10,13,20,21}$ Recent metaanalysis confirms this lower risk of progression in settings where the diagnosis of LGD is made more liberally, and thus likely overcalled. ${ }^{11}$ This is particularly common in U.S. cohort studies which observed lower annual progression rates of $1.8 \%$ to $2.7 \%$, when including cases with indefinite LGD or lacking in expert pathology review. ${ }^{6,22,23,24,25}$ In this study, in which all patients had a diagnosis of LGD confirmed by at least one expert GI pathologist, the annual rate of progression to HGD/EAC was $6.6 \%$ which is comparable to rates from Europe. . $^{71,12,13}$ This high annual progression rate is also similar to two landmark clinical trials on RFA for LGD (11.8\% in the SURF trial and 14\% in the AIM dysplasia trial), both of which excluded more than $30 \%$ of referred LGD cases following downgrading of the diagnosis by expert pathology review. ${ }^{10,13,21}$

Prior studies have suggested that RFA is effective in cancer risk reduction in clinical trial settings, with reduction of HGD/cancer risk ranging from 9-25\%. ${ }^{10,13}$ Our multicenter study represents the largest study to date to demonstrate the effectiveness of RFA for LGD in routine practice outside the setting of a clinical trial. Our endpoint, progression to HGD/ EAC, was the same endpoint used in the clinical trials. Our results were strikingly similar to 
the European SURF trial, in which $26.5 \%$ of patients with LGD progressed to HGD/EAC in the surveillance arm, while only $1.5 \%$ progressed after RFA at three years follow-up. ${ }^{13}$ This is important given that not all therapeutic interventions are as effective in clinical practice as when conducted in clinical trials. ${ }^{26,27,28}$ Taken together, the available data suggest a therapeutic benefit of RFA compared to surveillance for LGD confirmed by an expert pathologist.

Current practice guidelines suggest performance of endoscopic surveillance every 6 to 12 months after detection of LGD when the diagnosis is confirmed by an expert GI pathologist. ${ }^{3,29}$ Furthermore, some have questioned whether ablation should be reserved for those with HGD, arguing that it is more important to prevent EAC than HGD. ${ }^{14}$ However, HGD and intramucosal adenocarcinoma can be difficult to distinguish both on endoscopic biopsies and on esophagectomy specimens. ${ }^{30,31}$ Although our study was underpowered to assess the impact of RFA for LGD on the incidence of EAC, prior studies have observed up to $40 \%$ of patients who underwent esophagectomy for HGD had EAC in the pathology specimen. ${ }^{32,33}$ Thus, waiting for progression to HGD before implementing ablation therapy is likely to result in additional cases of EAC as compared to a strategy of RFA for LGD. Indeed, both cases of submucosal EAC in our study occurred in the absence of detection of HGD as an intermediate step. At least 6 progressors in the surveillance group ultimately required esophagectomy, and this may be an underestimate given that 20 of 36 (55.6\%) progressors were lost to follow up (Supplemental Table 1). Given the reported excellent safety profile of RFA for LGD, our data and that of clinical trials support the use of RFA for LGD confirmed by expert pathologists. ${ }^{10,13,34}$

Our study identified mucosal nodularity and multifocal dysplasia as independent predictors for progression to HGD or EAC. Several studies previously found both multifocal high- and low-grade dysplasia to be risk factors for progression to cancer. ${ }^{22,35,36,37}$ Taken together, this suggests utility in separation of surveillance biopsies for evaluation of multifocal dysplasia, with candidate patients being referred for endoscopic eradication at centers with endoscopic and pathologic expertise. However, even among patients with unifocal, flat LGD, progression rates were high; thus RFA should be discussed with all patients with LGD until better predictors of patients at low risk of progression can be identified.

Several biomarkers have been suggested to improve the diagnosis of LGD. The use of p53 immunohistochemistry has been suggested by the British Society of Gastroenterology as an adjunctive test and has been found to improve agreement on the diagnosis. ${ }^{29,38}$ Although this is a clinical laboratory based test that is commonly available, there are limitations to this test as false positives have been found in areas of reactive atypia. A more precise clinical test would be p53 fluorescent in situ hybridization which is less widely available and has increased cost. ${ }^{39}$ Other commonly involved genes in Barrett's esophagus include p16 abnormalities as well as evidence of chromosomal instability both of which could be assessed with immunohistochemistry and FISH respectively. These tests may better stratify risk of progression though data supporting their use to date are limited. ${ }^{40}$

Complete eradication of intestinal metaplasia was not achieved in $22.2 \%$ of RFA-treated patients during the study period. These patients may be at higher risk of recurrent dysplasia 
and subsequent progression to cancer. We expect that the effect of ablation in cancer risk reduction is more pronounced in patients who achieved complete eradication of intestinal metaplasia. The one progressor in the RFA cohort, who was lost to follow-up for over 7 months, emphasizes the need for early reassessment for complete eradication.

Mucosal nodularity has been associated with an increased risk of progression to adenocarcinoma, but is not typically associated with LGD. ${ }^{37}$ In our study, LGD patients with mucosal nodularity had a higher likelihood of progression to HGD/EAC than patients with only flat intestinal metaplasia with LGD. While it is conceivable that HGD or EAC may have been missed on targeted biopsies taken in these patients, this confounder was not imbalanced between the two groups, and our findings did not change when excluding these patients. Nonetheless, it is well known that EMR improves staging and diagnosis of Barrett's associated dysplasia, and that nodularity is predictive of underlying higher grade lesion that can be missed on biopsies alone. ${ }^{37,41,42,43}$

Our study period spanned over two decades and included a period prior to the implementation of RFA. This also overlapped a time preceding the development and widespread acceptance of EMR for nodular Barrett's and other endoscopic modalities and approaches now commonly used in diagnosis, staging, and treatment of Barrett's associated dysplasia. Furthermore, surveillance standards, the quality of endoscopic imaging in detection of visible lesions, and recognition of their importance have changed over time. Over one-third (13 of 36) of the progressors in the surveillance arm came from one center during the period from 1992 to 2005 prior to use of RFA. Nonetheless, the RFA associations were not time-varying; the risk of progression following RFA remained significantly lower after adjusting for the year of LGD diagnosis and when analyzing only cases starting followup in 2006.

There was a lag period of a median 122.5 days (IQR: 78.5,277) from the time of initial LGD detection to the first RFA session. This interval is comparable to similar studies. ${ }^{13}$ It is possible that LGD could have progressed to HGD/EAC prior to ablation within that short time period. Yet, assuming the highest progression rate found at one of our centers in the surveillance group of $10.6 \%$ per patient per year, an additional 3 patients would have progressed to HGD or IMC during this lag period, which would not have significantly impacted our results. Furthermore, a median of 2 (IQR: 1, 3) endoscopies were performed prior to ablation after the diagnosis of LGD, and these biopsies showed LGD and no HGD or EAC.

LGD can persist with stable LGD or progress to HGD or EAC as part of the natural history of the dysplasia to carcinoma sequence. When LGD is not detected on subsequent endoscopy, it could be due to overcall of the initial LGD, sampling error on the follow-up exam, or conceivably regression to non-dysplastic Barrett's. In our study, $31.2 \%$ of patients in the surveillance group did not have their diagnosis of LGD reproduced over time, which is similar to other studies, and was associated with shorter segment Barrett's in our study. ${ }^{10,13}$ This potential sampling error demonstrates the challenge of subsequent management of patients diagnosed with LGD and argues for the need for confirmed pathology results by a pathologist with extensive experience in the interpretation of Barrett's 
associated dysplasia/neoplasia. Future studies should compare progression rates among patients with LGD confirmed by expert pathologists that is not detected on subsequent endoscopy to those in whom LGD is confirmed on two consecutive endoscopies.

A limitation of this study is the lack of generalizability to community settings. Our study consisted of a referred population with confirmed pathology at experienced referral centers. These patients had a high neoplastic progression rate; one that may not be representative of LGD patients managed in community settings and emphasizes the importance of access to expert GI pathologists.

Another potential limitation is that confirmation of LGD by multiple expert pathologists was not conducted in every case. While a high degree of interobserver variability can be seen in the histological diagnosis of LGD, it is highly unlikely that this was overcalled differentially in the RFA group to explain the difference in outcomes between the two groups. ${ }^{6,21}$

Although central pathology review for standardized interpretation would have strengthened this study, this is not readily performed in referral practices.

Likewise, the approach to endoscopic follow-up intervals and biopsies in the two groups was not the same. Rigorous adherence to surveillance protocols outside of trial settings can be difficult. ${ }^{44,45}$ However many of the endoscopists in this study were investigators in the initial randomized clinical trial of RFA and tried to follow similar surveillance protocols as in the trial. ${ }^{9,10}$ In addition, patients in both arms received a high frequency of endoscopies with biopsies following intervention, with closer surveillance after RFA (Supplemental Figure 1), making it unlikely that HGD or EAC was differentially missed.

In conclusion, our results in conjunction with the recent clinical trial data suggest that endoscopic ablation has potential benefit over endoscopic surveillance in the management of referred patients with LGD confirmed by an expert pathologist. ${ }^{13}$ The high neoplastic progression rates in patients undergoing surveillance alone, the low NNT to avoid progression to HGD or cancer, and the excellent safety profile of RFA reported to date now provide additional evidence supporting ablation for Barrett's patients with confirmed LGD. Confirmation of LGD by an expert GI pathologist is critical prior to a decision to ablate.

\section{Supplementary Material}

Refer to Web version on PubMed Central for supplementary material.

\section{Acknowledgments}

This work was supported by the NIH/NIDDK T32 DK007740 (Clinical Epidemiology Training in Gastroenterology), the NIDDK 1 K08 DK084347-01, the NIH K24-DK078228, the NIH/NCI U54-CA163004, the NIH/NIDDK P30DK050306 Center for Molecular Studies in Digestive and Liver Diseases, and the NIH/NCI P01CA098101 and institutional funds.

\section{Abbreviations used in this paper}

EAC Esophageal adenocarcinoma 


$\begin{array}{ll}\text { BE } & \text { Barrett's esophagus } \\ \text { HGD } & \text { High-grade dysplasia } \\ \text { IMC } & \text { Intramucosal carcinoma } \\ \text { LGD } & \text { Low-grade dysplasia } \\ \text { RFA } & \text { Radiofrequency ablation } \\ \text { IM } & \text { Intestinal metaplasia } \\ \text { EMR } & \text { endoscopic mucosal resection } \\ \text { CE-IM } & \text { Complete eradication of intestinal metaplasia }\end{array}$

\section{References}

1. Rasool S, Ganai AB, Syed Sameer A, et al. Esophageal cancer: associated factors with special reference to the Kashmir Valley. Tumori. 2012; 98:191-203. [PubMed: 22677984]

2. Brown LM, Devesa SS, Chow WH. Incidence of adenocarcinoma of the esophagus among white Americans by sex, stage, and age. J Natl Cancer Inst. 2008; 100:1184-1187. [PubMed: 18695138]

3. Spechler SJ, Sharma P, Souza RF, et al. American Gastroenterological Association medical position statement on the management of Barrett's esophagus. Gastroenterology. 2011; 140:1084-1091. [PubMed: 21376940]

4. Bennett C, Vakil N, Bergman J, et al. Consensus Statements for Management of Barrett's Dysplasia and Early-Stage Esophageal Adenocarcinoma, Based on a Delphi Process. Gastroenterology. 2012; 143:336-346. [PubMed: 22537613]

5. Wani S, Mathur S, Sharma P. How to manage a Barrett's esophagus patient with low-grade dysplasia. Clin Gastroenterol Hepatol. 2009; 7:27-32. [PubMed: 18986846]

6. Wani S, Falk GW, Post J, et al. Risk factors for progression of low-grade dysplasia in patients with Barrett's esophagus. Gastroenterology. 2011; 141:1179-1186. [PubMed: 21723218]

7. Curvers WL, ten Kate FJ, Krishnadath KK, et al. Low-grade dysplasia in Barrett's esophagus: overdiagnosed and underestimated. Am J Gastroenterol. 2010; 105:1523-1530. [PubMed: 20461069]

8. Kastelein F, van Olphen S, Steyerberg EW, et al. Surveillance in patients with long-segment Barrett's oesophagus: a cost-effectiveness analysis. Gut. 2014 Jul 18. Epub ahead of print.

9. Shaheen NJ, Overholt BF, Sampliner RE, et al. Durability of radiofrequency ablation in Barrett's esophagus with dysplasia. Gastroenterology. 2011; 141:460-468. [PubMed: 21679712]

10. Shaheen NJ, Sharma P, Overholt BF, et al. Radiofrequency ablation in Barrett's esophagus with dysplasia. N Engl J Med. 2009; 360:2277-2288. [PubMed: 19474425]

11. Singh S, Manickam P, Amin AV, et al. Incidence of esophageal adenocarcinoma in Barrett's esophagus with low-grade dysplasia: a systematic review and meta-analysis. Gastrointest Endosc. 2014; 79:897-909. [PubMed: 24556051]

12. Duits LC, Phoa KN, Curvers WL, et al. Barrett's esophagus patients with low-grade dysplasia can be accurately risk-stratified after histological review by an expert pathology panel. Gut. 2015; 64:700-706. [PubMed: 25034523]

13. Phoa KN, van Vilsteren FG, Weusten BL, et al. Radiofrequency ablation vs endoscopic surveillance for patients with Barrett esophagus and low-grade dysplasia: a randomized clinical trial. JAMA. 2014; 311:1209-1217. [PubMed: 24668102]

14. Rubenstein JH, Kwon RS. Radiofrequency Ablation for Barrett's Esophagus With Low-Grade Dysplasia: A Hammer Looking for a Nail. Gastroenterology. 2014; 147:706-707. [PubMed: 25051059] 
15. Riddell RH, Goldman H, Ransohoff DF, et al. Dysplasia in inflammatory bowel disease: standardized classification with provisional clinical applications. Hum Pathol. 1983; 14:931-968. [PubMed: 6629368]

16. Montgomery E, Bronner MP, Goldblum JR, et al. Reproducibility of the diagnosis of dysplasia in Barrett esophagus: a reaffirmation. Hum Pathol. 2001; 32:368-378. [PubMed: 11331953]

17. Lim CH, Treanor D, Dixon MF, et al. Low-grade dysplasia in Barrett's esophagus has a high risk of progression. Endoscopy. 2007; 39:581-587. [PubMed: 17611911]

18. Bhat S, Coleman HG, Yousef F, et al. Risk of malignant progression in Barrett's esophagus patients: results from a large population-based study. J Natl Cancer Inst. 2011; 103:1049-1057. [PubMed: 21680910]

19. Hvid-Jensen F, Pedersen L, Drewes AM, et al. Incidence of adenocarcinoma among patients with Barrett's esophagus. N Engl J Med. 2011; 365:1375-1383. [PubMed: 21995385]

20. Skacel M, Petras RE, Gramlich TL, et al. The diagnosis of low-grade dysplasia in Barrett's esophagus and its implications for disease progression. Am J Gastroenterol. 2000; 95:3383-3387. [PubMed: 11151865]

21. Mitlyng BL, Leon S, Ganz RA. Esophageal adenocarcinoma in Barrett's esophagus with lowgrade dysplasia. Gastrointest Endosc. 2015; 81:484. [PubMed: 25616761]

22. Thota PN, Lee HJ, Goldblum, et al. Risk stratification of patients with Barrett's esophagus and low-grade dysplasia or indefinite for dysplasia. Clin Gastroenterol Hepatol. 2015; 13:459-465. [PubMed: 25102445]

23. Bergman JJ, Corley DA. Barrett's esophagus: who should receive ablation and how can we get the best results? Gastroenterology. 2012; 143:524-526. [PubMed: 22841734]

24. Dulai GS, Shekelle PG, Jensen DM, et al. Dysplasia and risk of further neoplastic progression in a regional Veterans Administration Barrett's cohort. Am J Gastroenterol. 2005; 100:775-783. [PubMed: 15784018]

25. Jung KW, Talley NJ, Romero Y, et al. Epidemiology and natural history of intestinal metaplasia of the gastroesophageal junction and Barrett's esophagus. Am J Gastroenterol. 2011; 106:1447-1455. [PubMed: 21483461]

26. Ilnyckyj A, Shanahan F, Anton PA, et al. Quantification of the placebo response in ulcerative colitis. Gastroenterology. 1997; 112:1854-1858. [PubMed: 9178676]

27. Lewis JD, Lichtenstein GR, Deren JJ, et al. Rosiglitazone for active ulcerative colitis: a randomized placebo-controlled trial. Gastroenterology. 2008; 134:688-695. [PubMed: 18325386]

28. Milestone AN, Iacucci M, Ghosh S. Is rosiglitazone a promising treatment for ulcerative colitis? Nat Clin Pract Gastroenterol Hepatol. 2008; 5:486-487. [PubMed: 18711416]

29. Fitzgerald RC, di Pietro M, Ragunath K, et al. British Society of Gastroenterology guidelines on the diagnosis and management of Barrett's esophagus. Gut. 2014; 63:7-42. [PubMed: 24165758]

30. Ormsby AH, Petras RE, Henricks WH, et al. Observer variation in the diagnosis of superficial esophageal adenocarcinoma. Gut. 2002; 51:671-676. [PubMed: 12377805]

31. Downs-Kelly E, Mendelin JE, Bennett AE, et al. Poor interobserver agreement in the distinction of high-grade dysplasia and adenocarcinoma in pretreatment Barrett's esophagus biopsies. Am J Gastroenterol. 2008; 103:2333-2340. [PubMed: 18671819]

32. Pellegrini CA, Pohl D. High-grade dysplasia in Barrett's esophagus: surveillance or operation? J Gastrointest Surg. 2000; 4:131-134. [PubMed: 10885959]

33. Prasad GA, Wang KK, Buttar NS, et al. Long-term survival following endoscopic and surgical treatment of high-grade dysplasia in Barrett's esophagus. Gastroenterology. 2007; 132:1226-1233. [PubMed: 17408660]

34. Orman ES, Li N, Shaheen NJ. Efficacy and Durability of Radiofrequency Ablation for Barrett's Esophagus: Systematic Review and Meta-analysis. Clin Gastroenterol Hepatol. 2013; 11:12451255. [PubMed: 23644385]

35. Srivastava A, Hornick JL, Li X, et al. Extent of low-grade dysplasia is a risk factor for the development of esophageal adenocarcinoma in Barrett's esophagus. Am J Gastroenterol. 2007; 102:483-493. [PubMed: 17338734]

36. Tharavej C, Hagen JA, Peters JH, et al. Predictive factors of coexisting cancer in Barrett's highgrade dysplasia. Surg Endosc. 2006; 20:439-443. [PubMed: 16437272] 
37. Buttar NS, Wang KK, Sebo TJ, et al. Extent of high-grade dysplasia in Barrett's esophagus correlates with risk of adenocarcinoma. Gastroenterology. 2001; 120:1630-1639. [PubMed: 11375945]

38. Kastelein F, Biermann K, Steyerberg EW, et al. on behalf of the ProBar-study group. Aberrant p53 protein expression is associated with an increased risk of neoplastic progression in patients with Barrett's oesophagus. Gut. 2013; 62:1676-1683. [PubMed: 23256952]

39. Davelaar AL, Calpe S, Lau L, et al. Aberrant TP53 detected by combining immunohistochemistry and DNA-FISH improves Barrett's esophagus progression prediction: a prospective follow-up study. Genes Chromosomes Cancer. 2015; 54:82-90. [PubMed: 25284618]

40. Gregson EM, Fitzgerald RC. Biomarkers for dysplastic Barrett's: ready for prime time? World J Surg. 2015; 39:568-577. [PubMed: 24844657]

41. Prasad GA, Bansal A, Sharma P, et al. Predictors of progression in Barrett's esophagus: current knowledge and future directions. Am J Gastroenterol. 2010; 105:1490-1502. [PubMed: 20104216]

42. Pech O, May A, Manner H, et al. Long-term efficacy and safety of endoscopic resection for patients with mucosal adenocarcinoma of the esophagus. Gastroenterology. 2014; 146:652-660. [PubMed: 24269290]

43. Small AJ, Sutherland SE, Hightower JS, et al. Comparative risk of recurrence of dysplasia and carcinoma after endoluminal eradication therapy of high-grade dysplasia versus intramucosal carcinoma in Barrett's esophagus. Gastrointest Endosc. 2015; 81:1158-1166. [PubMed: 25650071]

44. Abrams JA, Kapel RC, Lindberg GM, et al. Adherence to biopsy guidelines for Barrett's esophagus surveillance in the community setting in the United States. Clin Gastroenterol Hepatol. 2009; 7:736-742. [PubMed: 19268726]

45. Menezes A, Tierney A, Yang YX, et al. Adherence to the 2011 American Gastroenterological Association medical position statement for the diagnosis and management of Barrett's esophagus. Dis Esophagus. 2014 May 21. Epub ahead of print. Author names in bold designate shared co-first authors.

\section{Contributions of the authors were as follows}

\begin{tabular}{|c|c|c|c|c|c|c|c|}
\hline & $\begin{array}{l}\text { Study } \\
\text { concept } \\
\text { and } \\
\text { design }\end{array}$ & Acquisition of data & $\begin{array}{c}\text { Analysis and } \\
\text { interpretation } \\
\text { of data }\end{array}$ & Drafting of manuscript & $\begin{array}{c}\begin{array}{c}\text { Critical } \\
\text { revision of } \\
\text { manuscript } \\
\text { for }\end{array} \\
\text { important } \\
\text { intellectual } \\
\text { content }\end{array}$ & Statistical analysis & Obtained \\
\hline Small AJ & $\mathrm{X}$ & $\mathrm{x}$ & $\mathrm{X}$ & $\mathrm{X}$ & $\mathrm{X}$ & $\mathrm{X}$ & \\
\hline Araujo JL & & $\mathrm{x}$ & & & $\mathrm{X}$ & & \\
\hline Leggett CL & & $\mathrm{x}$ & & & $\mathrm{X}$ & & \\
\hline Mendelson AH & & $\mathrm{X}$ & & & $\mathrm{X}$ & & \\
\hline Agarwalla A & & $\mathrm{X}$ & & & $\mathrm{X}$ & & \\
\hline Abrams JA & & $\mathrm{x}$ & & & $\mathrm{X}$ & & \\
\hline Lightdale CJ & & $\mathrm{X}$ & & & $\mathrm{X}$ & & \\
\hline Wang TC & & & & & $\mathrm{X}$ & & $\mathrm{X}$ \\
\hline Iyer PG & & $\mathrm{x}$ & & & $\mathrm{X}$ & & \\
\hline Wang KK & & $\mathrm{X}$ & & & $\mathrm{X}$ & & $\mathrm{X}$ \\
\hline Rustgi AK & & & & & $\mathrm{X}$ & & $\mathrm{X}$ \\
\hline Ginsberg GG & & & & & $\mathrm{X}$ & & \\
\hline Forde KA & & & & & $\mathrm{X}$ & $\mathrm{X}$ & \\
\hline
\end{tabular}




\begin{tabular}{|l|c|c|c|c|c|c|c|}
\hline & $\begin{array}{c}\text { Study } \\
\text { concept } \\
\text { and } \\
\text { design }\end{array}$ & Acquisition of data & $\begin{array}{c}\text { Analysis and } \\
\text { interpretation } \\
\text { of data }\end{array}$ & Drafting of manuscript & $\begin{array}{c}\text { Critical } \\
\text { revision of } \\
\text { manuscript } \\
\text { for } \\
\text { important } \\
\text { intellectual } \\
\text { content }\end{array}$ & Statistical analysis & Obtained \\
\hline Gimotty PA & & & $\mathrm{X}$ & & $\mathrm{X}$ & $\mathrm{X}$ & \\
\hline Lewis JD & $\mathrm{X}$ & & $\mathrm{X}$ & & $\mathrm{X}$ & $\mathrm{X}$ & $\mathrm{X}$ \\
\hline Falk GW & $\mathrm{X}$ & & $\mathrm{X}$ & & $\mathrm{X}$ & & \\
\hline Bewtra M & $\mathrm{X}$ & & $\mathrm{X}$ & $\mathrm{X}$ & $\mathrm{X}$ & $\mathrm{X}$ & \\
\hline
\end{tabular}

\section{Disclosure}

Drs. Small, Araujo, Leggett, Mendelson, and Agarwalla have no conflicts of interest and nothing to disclose.

Dr. Abrams has served as a consultant to $\mathrm{C} 2$ Therapeutics. He has received research support from C2 Therapeutics and Covidien.

Dr. Lightdale has served as a consultant to Boston Scientific, C2 Therapeutics, CSA Medical, Mauna Kea Technologies, and NinePoint Medical. He has received royalties from Cook Medical.

Dr. Wang has no conflicts of interest and nothing to disclose.

Dr. Iyer has received research support from Takeda Pharmaceuticals.

Dr. Wang has received research support from BaRRx, Pinnacle Pharma, and CSA.

Drs. Rustgi, Ginsberg, Forde, and Gimotty have no conflicts of interest and nothing to disclose.

Dr. Lewis has served as a consultant to Takeda, Amgen, Millennium Pharmaceuticals, Pfizer, Abbott, Prometheus, Nestle, Lilly, and Shire. He has received research funding from Shire, Takeda, and Centocor.

Dr. Falk serves as a consultant to CDX and receives research support from CDX.

Dr. Bewtra has received research support from Janssen and Imedex. 


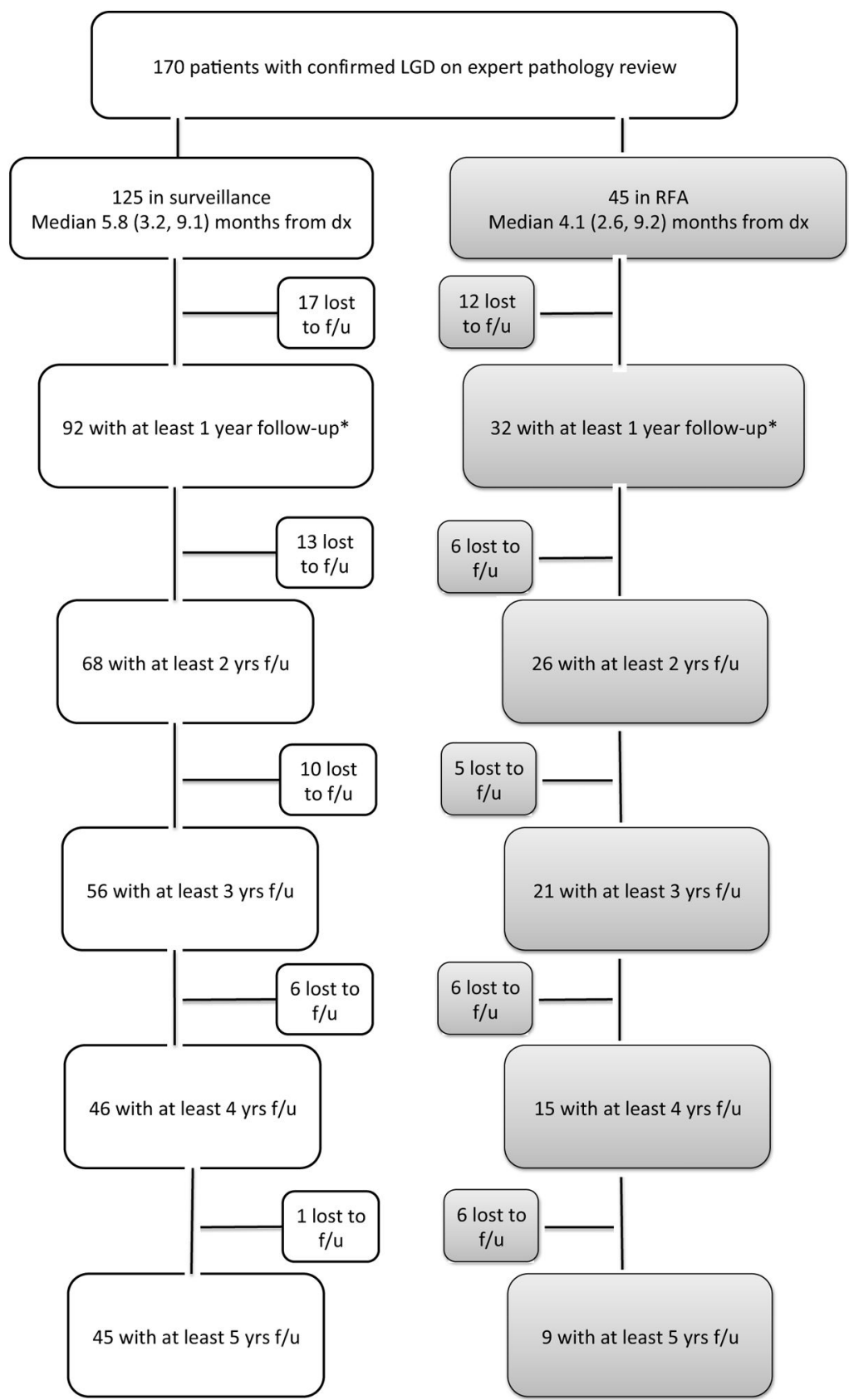

Figure 1.

Flow Diagram of Patients Meeting Study Criteria

*Follow-up period starting from date of first intervention of LGD until date of last endoscopy with biopsies in the medical chart 

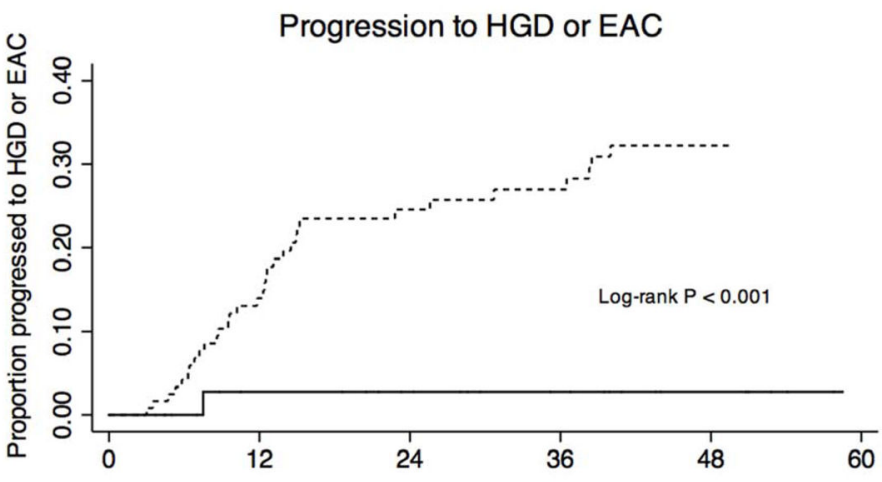

Number at risk

Follow-up, months

$\begin{array}{llllllllllll}\text { Surveillance } & 125 & (16) & 92 & (11) & 68 & \text { (2) } & 56 & \text { (4) } & 46 & \text { (0) } & 45\end{array}$

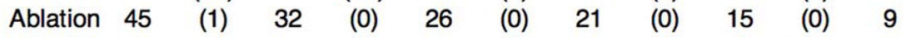

Figure 2.

Progression to High-Grade Dysplasia or Adenocarcinoma from Time of First RFA or Surveillance Endoscopy. 
Table 1

Patient Demographics And Disease-Specific Characteristics

\begin{tabular}{|c|c|c|c|}
\hline Characteristic & Ablation $(\mathrm{N}=45)$ & Surveillance $(\mathbf{N}=\mathbf{1 2 5})$ & $P$ value \\
\hline \multicolumn{4}{|l|}{ By Center } \\
\hline Univ. of Pennsylvania & $5(11.1)$ & $53(42.4)$ & $<0.001$ \\
\hline Columbia & $10(22.2)$ & $37(29.6)$ & 0.34 \\
\hline Mayo Clinic & $30(66.7)$ & $35(28)$ & $<0.001$ \\
\hline Age, median (IQR), y & $62(56,58)$ & $65(56,73)$ & 0.15 \\
\hline Men, No. (\%) & $36(80)$ & $103(82.4)$ & 0.44 \\
\hline White race/ethnicity, No. (\%) & $43(95.6)$ & $121(96.8)$ & 0.50 \\
\hline BMI, median (IQR) ${ }^{*}$ & $28.9(27,32.2)$ & $28.5(26.2,31.7)$ & 0.39 \\
\hline \multicolumn{4}{|l|}{ Tobacco use, No. $(\%)^{*}$} \\
\hline Current at time of $\mathrm{dx}$ & $5(13.2)$ & $6(7.1)$ & 0.23 \\
\hline Non-current & $33(86.8)$ & $78(92.9)$ & \\
\hline \multicolumn{4}{|l|}{ Use of Proton Pump Inhibitor, No. $(\%)^{*}$} \\
\hline Non-user & $1(2.5)$ & $23(26.7)$ & $<0.001$ \\
\hline User $^{* *}$ & $39(97.5)$ & $63(73.3)$ & \\
\hline \multicolumn{4}{|l|}{ Use of Aspirin, No. $(\%)^{*}$} \\
\hline Non-user & $22(56.4)$ & $51(62.2)$ & 0.54 \\
\hline User $^{\#}$ & 17 (43.6) & $31(37.8)$ & \\
\hline Length of Barrett's esophagus, median (IQR) & $5(3,6)$ & $5(3,8)$ & 0.42 \\
\hline Presence of Nodularity, No. (\%) & $3(6.6)$ & $13(10.4)$ & 0.45 \\
\hline Multifocal dysplasia ${ }^{\wedge}$ No. $(\%)$ & $19 / 45(42.2)$ & $28 / 84(33.3)$ & 0.13 \\
\hline Incident cases ${ }^{\wedge}$, No. $(\%)$ & $19 / 45(42.2)$ & $57 / 90(63.3)$ & 0.02 \\
\hline Confirmed with Second Pathology Specimen ${ }^{\circ}$, No. (\%) & $27 / 45(60)$ & | 43/90 (47.8) & 0.14 \\
\hline Follow-up period per patient, months, median (IQR) ${ }^{\mathscr{I}}$ & $29.6(8.8,54.1)$ & $28.3(10.7,78.5)$ & 0.32 \\
\hline Total endoscopies performed during follow-up period per patient, No., median (IQR) & $9(6,12)$ & $5(3,8)$ & $<0.001$ \\
\hline
\end{tabular}

* Sample sizes with complete data for BMI: $\mathrm{n}=37$ [ablation], $\mathrm{n}=75$ [surveillance]; for Tobacco use: $\mathrm{n}=38$ [ablation], $\mathrm{n}=84$ [surveillance]; for Proton Pump Inhibitor use: $\mathrm{n}=40$ [ablation], $\mathrm{n}=86$ [surveillance]; aspirin use: $\mathrm{n}=39$ [ablation], $\mathrm{n}=82$ [surveillance]

**

All users on twice daily PPI except 3 patients in ablated group and 20 in the surveillance group. 
\# All users on low dose aspirin $(81 \mathrm{mg})$ except one patient in the ablated group and two patients in the surveillance group on full dose aspirin (325 $\mathrm{mg}$ ).

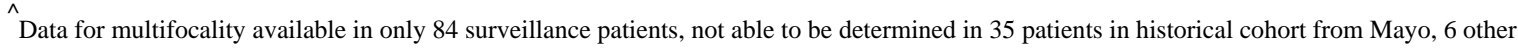
patients had biopsies placed in same specimen jar.

$\wedge \wedge$

At least one endoscopy with biopsies documenting Barrett's without dysplasia preceding diagnosis of LGD during the study period. Recorded in all ablated patients and 90 surveillance patients, not able to be determined in 35 patients in historical cohort from Mayo.

'At least two endoscopies with biopsies documenting Barrett's with LGD during study period. Data for this variate available in only 90 surveillance patients, not able to be determined in 35 patients in historical cohort from Mayo.

${ }^{I}$ Time from initial intervention (first RFA or surveillance EGD) to progression or last endoscopy with biopsies in chart 


\section{Table 2}

\section{Effectiveness of RFA*}

\begin{tabular}{|l|c|}
\hline Outcome & No. Patients (\%) \\
\hline No. of RFA sessions per pt, median (IQR) & $2(2,3)$ \\
\hline Complete eradication of dysplasia (CE-D) at end of treatment & $43 / 45(95.6)$ \\
\hline No. of RFA sessions to CE-D, median (IQR) & $2(1,3)$ \\
\hline Complete eradication of intestinal metaplasia (CE-IM) at end of treatment & $35 / 45(77.8)$ \\
\hline No. of RFA sessions to CE-IM, median (IQR) & $3(2,4)$ \\
\hline Sustained CE-D through to end of follow-up & $35 / 43(81.4)$ \\
\hline No. of EGDs per pt after CRD achieved, median (IQR) & $4(2,6)$ \\
\hline
\end{tabular}

Total of 118 RFAs performed on 45 patients. 
Table 3

Relative Effectiveness of Ablation to Prevent Progression of LGD to HGD or Cancer in the Full Cohort and Subgroups

\begin{tabular}{|l|c|c|c|c|}
\hline & Hazard Ratio $\mathbf{9 5 \%}$ CI) & P value & $\begin{array}{c}\text { Adjusted Hazard Ratio } \\
(\mathbf{9 5 \%} \text { CI) }\end{array}$ & $P$ value \\
\hline \multicolumn{1}{|c|}{ Risk of Progression After RFA } & $0.08[0.01-0.61]$ & 0.02 & $0.06[0.008-0.48]^{* *}$ & 0.008 \\
\hline Sensitivity Analysis, Variable Tested on Effect of RFA & & & \\
\hline $\begin{array}{l}\text { Only patients with LGD diagnosed from 2006 to end of study period (excluded all cases } \\
\text { diagnosed before 2006) }\end{array}$ & & $0.09[0.01-0.73]$ & 0.02 \\
\hline Flat LGD (excluded all patients with nodularity) $)^{\text {Il }}$ & & $0.10[0.01-0.76]$ & 0.03 \\
\hline $\begin{array}{l}\text { Progressors after >1 year (excluded all patients who progressed within the 1st year in } \\
\text { surveillance group) }\end{array}$ & & $0.13[0.02-0.95]$ & 0.04 \\
\hline
\end{tabular}

* Cox proportional hazard model after adjusting for incident diagnosis, confirmation with second pathology specimen, and multifocality. Incident diagnosis and confirmed LGD (with second specimen) were both confounders on progression and remained in the final model.

Y*ar of diagnosis was not found to be an effect modifier nor a confounder. aHR=0.05; 95\% CI, $0.007-0.43 ; P=0.006$ after adjusting for year of diagnosis in addition to incident diagnosis, confirmed with second pathology, and multifocality.

\#

sitivity analysis on time of diagnosis and follow-up after excluding patients who had LGD diagnosed before 2006 (0/5 RFA and 27/89 surveillance progressed for those diagnosed before 2006). Of patients diagnosed in or after 2006, 1/40 RFA and 9/36 surveillance progressed.

${ }^{I}$ Sensitivity analysis on flat LGD after excluding patients who had presence of nodularity on index endoscopy. Of patients with flat LGD, 1/42 RFA and 29/112 surveillance progressed. $18.6 \%$ of the patients with flat, unifocal LGD progressed in the surveillance group.

Sensitivity analysis on early progressors. Of patients with at least one year follow-up and excluding patients in surveillance who progressed within the first year from initial surveillance, 1/33 RFA and 20/92 surveillance progressed. 
Table 4

Progression Rates to HGD or Cancer from Time of Intervention ${ }^{\wedge}$

\begin{tabular}{|l|l|l|l|l|}
\hline & \multicolumn{4}{|c|}{ Progressors / Non-progressors * } \\
\hline Follow-up & Ablation & $\%^{\#}$ & Surveillance & $\%$ \\
\hline Yr 1 & $1 / 32$ & 3.0 & $16 / 92$ & 14.8 \\
\hline Yr 2 & $0 / 26$ & 0 & $11 / 68$ & 13.9 \\
\hline Yr 3 & $0 / 21$ & 0 & $2 / 56$ & 3.4 \\
\hline Yr 4 & $0 / 15$ & 0 & $4 / 46$ & 8.0 \\
\hline Yr 5 & $0 / 9$ & 0 & $0 / 45$ & 0 \\
\hline
\end{tabular}

* progressors within the $\mathrm{yr} /$ nonprogressors with at least that yr of follow-up

$\#$

\# = progressors/ (nonprogressors with at least yr follow-up and progressors within that yr)

Overall progression during follow-up period was 1 IMC (2.2\%) in RFA group vs. 29 HGD, 5 IMC, and 2 submucosal EAC (28.8\%) in surveillance group $(P<0.001)$. Median time from initial intervention to progression to HGD or cancer was 7.5 months in RFA and 12.5 months (IQR: 7.4, 24.2) in surveillance. Progression to HGD or cancer when stratified by center as follows: University of Pennsylvania 1/5 RFA and 19/53 surveillance, Columbia 0/10 RFA and 4/37 surveillance, Mayo Clinic 0/30 RFA and 13/35 surveillance. 


\section{Table 5}

Predictors of Progression to HGD or EAC Among Patients Undergoing Surveillance Endoscopy Without Ablation

\begin{tabular}{|l|c|c|c|c|}
\hline Risk Factor (no. of patients with complete data for factor) & \multicolumn{2}{|c|}{ Univariate Model (N=125) } & \multicolumn{2}{|c|}{ Multivariate Model (N=77) } \\
\hline & Hazard Ratio (95\% CI) & $P$ value & $\begin{array}{c}\text { Adjusted Hazard Ratio (95\% } \\
\text { CI) }\end{array}$ & $P$ value \\
\hline Age, per yr (125) & $1.02[0.99-1.05]$ & $\mathbf{0 . 1 9}$ & & \\
\hline BMI, per unit (75) & $0.98[0.90-1.06]$ & 0.57 & & 0.15 \\
\hline Maximum length of Barrett's segment, per cm (121) & $1.16[1.07-1.25]$ & $<\mathbf{0 . 0 1}$ & $1.08[0.97-1.19]$ & \\
\hline Incident LGD ${ }^{*}$ (90) & $0.45[0.19-1.02]$ & $\mathbf{0 . 0 6}$ & & \\
\hline Persistent LGD ${ }^{\#}$ (89) & $3.41[1.37-8.44]$ & $\mathbf{0 . 0 1}$ & & $\mathbf{0 . 0 2}$ \\
\hline Presence of nodularity (116) & $3.00[1.30-6.93]$ & $\mathbf{0 . 0 1}$ & $\mathbf{3 . 1 2}[\mathbf{1 . 1 8}-\mathbf{8 . 2 5}]$ & $\mathbf{0 . 0 0 2}$ \\
\hline Multifocal dysplasia (90) & $3.65[2.03-6.56]$ & $<\mathbf{0 . 0 1}$ & $\mathbf{3 . 0 9}[\mathbf{1 . 4 9 - 6 . 4 1 ]}$ & \\
\hline Tobacco (84, ref: not active) & $0.89[0.34-2.38]$ & 0.82 & & $0.42[0.10-1.78]$ \\
\hline Aspirin (82, ref: non-user) & $0.40[0.15-1.08]$ & $\mathbf{0 . 0 7}$ & & 0.24 \\
\hline Use of PPI (86, ref: non-user) & $1.04[0.45-2.37]$ & 0.93 & & \\
\hline Diagnosis after 2006 (125) & $1.12[0.52-2.40]$ & 0.77 & & \\
\hline
\end{tabular}

* Based on 125 patients; 36 progressors and 89 non-progressors at two-years from initial surveillance endoscopy. Hazard ratios derived from Cox regression.

**

Only 7 candidate factors with p values below 0.20 in the univariate analysis or with evidence of effect modification or confounding were considered for the final multivariate analysis. Age, incident cases, and persistent LGD were not statistically significant associated with progression in the final model ( $\mathrm{p}>0.05)$ and were removed. Length of Barrett's and use of aspirin were not statistically significantly associated with progression but were retained in the final model because removing them resulted in a $>15 \%$ change in HR for nodularity and multifocality. Patients with missing data for candidate predictors in the final multivariate model were excluded. CI denotes confidence interval.

$\wedge$

Incident LGD defined as having had surveillance endoscopies with Barrett's without dysplasia preceding the diagnosis of LGD (i.e. diagnosis of non-dysplastic Barrett's prior to diagnosis of LGD captured within study period)

\# Persistent LGD defined as patients who had at least two separate endoscopies with a diagnosis of LGD during the study period as compared to only one endoscopy session demonstrating biopsies with LGD. 